\title{
THE GERMAN HISTORY OF CONCEPTS AND THE HISTORY OF POLITICAL AND LEGAL DOCTRINES: FACETS OF INTERACTION ${ }^{1}$
}

\author{
Kirill S. Korovin \\ Ural State Law University, Yekaterinburg, Russian Federation
}

\begin{abstract}
German history of concepts became popular after the translation into Russian of some articles from "The Historical Dictionary of Socio-Political Language in Germany". This event is remarkable for legal science, since legal concepts are of particular importance for both the legislator and legal scientists when developing legal doctrine. The purpose of the paper is to apply a historical and conceptual approach to the study of state-legal phenomena in the history of political and legal doctrines. Methods: the methodological basis of this study is a systematic approach that allows to structure the constituent elements of the German history of concepts, as well as a structural and functional one, thanks to which the application of specific elements in practice was shown. Results: as a result of the analysis of the German experience of studying concepts, the author made conclusions that reflect the possibility of its use in law. First of all, the classification of concepts used in the dictionary is important. It allows you to structure and systematize the concepts used in the political and legal doctrines. The processes of transformation of concepts described methodologically by the Germans can be analyzed by analogy in Russian historical and legal science. The context of the emergence and evolution of the concepts reflects the fundamental changes in society and the state, so its description is necessary to explain the features of legal concepts. Conclusions: the adaptation of historical concepts with the help of modern legal language to the terminological apparatus of the theory of state and law is possible through the diachronic principle. The linguistic basis of the German dictionary is certainly interesting for lawyers from the point of view that the distinction between terms and concepts contributes to the improvement of legal techniques. Thus, the German history of concepts is largely interrelated with the history of political and legal doctrines, and further development of this issue is required.
\end{abstract}

Key words: history of concepts, history of political and legal doctrines, legal discourse, legal concepts, history of state and law, legal science, jurisprudence.

Citation. Korovin K.S. The German History of Concepts and the History of Political and Legal Doctrines: Facets of Interaction. Legal Concept $=$ Pravovaya paradigma, 2020, vol. 19, no. 4, pp. 55-62. (in Russian). DOI: https://doi.org/10.15688/lc.jvolsu.2020.4.7

УДК 340.12

Дата поступления статьи: 01.11.2020

ББК 67.1

Дата принятия статьи: 20.11.2020

\section{НЕМЕЦКАЯ ИСТОРИЯ ПОНЯТИЙ И ИСТОРИЯ ПОЛИТИЧЕСКИХ И ПРАВОВЫХ УЧЕНИЙ: ГРАНИ ВЗАИМОДЕЙСТВИЯ 1}

\footnotetext{
Кирилл Сергеевич Коровин

Уральский государственный юридический университет, г. Екатеринбург, Российская Федерация

Введение: немецкая история понятий стала популярной после перевода на русский язык некоторых статей из «Исторического словаря общественно-политического языка в Германии». Для юридической науки данное событие является примечательным, поскольку правовые понятия представляют особую важность как для законодателя, так и для ученых-юристов при разработке правовой доктрины. Цель статьи - применение историко-понятийного подхода к исследованию государственно-правовых феноменов в рамках истории политических и правовых учений. Методы: методологической основой данного исследования являются системный подход, позволяющий структурировать составные элементы немецкой истории понятий, а также структурно-функциональный, благодаря которому было показано применение конкретных элементов на
} 
практике. Результаты: в процессе анализа немецкого опыта изучения понятий автором была показана возможность использования данного подхода в юриспруденции. Прежде всего важной представляется классификация понятий, используемая в словаре. Она позволяет структурировать и систематизировать понятия, содержащиеся в политико-правовых учениях. Процессы трансформации понятий, методологически описываемые немцами, по аналогии могут быть проанализированы в российской историко-правовой науке. Контекст возникновения и эволюции понятий отражает коренные изменения в обществе и государстве, поэтому необходимо его изучение для объяснения особенностей юридических понятий. Выводы: было установлено, что адаптация исторических понятий при помощи современного юридического языка к терминологическому аппарату теории государства и права возможна посредством диахронного принципа. Лингвистический базис немецкого словаря интересен, безусловно, для юристов с той точки зрения, что различение терминов и понятий способствует совершенствованию юридической техники. Таким образом, немецкая история понятий во многом взаимосвязана с историей политических и правовых учений, и требуется дальнейшая разработка этой проблематики.

Ключевые слова: история понятий, история политических и правовых учений, правовой дискурс, юридические понятия, история государства и права, юридическая наука, юриспруденция.

Цитирование. Коровин К. С. Немецкая история понятий и история политических и правовых учений: грани взаимодействия // Legal Concept = Правовая парадигма. - 2020. - T. 19, № 4. - С. 55-62. - DOI: https:// doi.org/10.15688/lc.jvolsu.2020.4.7

\section{Введение}

История понятий в России стала магистральным междисциплинарным полем исследований в гуманитарных и социальных науках. Для юриспруденции данный методологический подход является актуальным, поскольку в изучении происхождения понятий, в установлении их истинного, исконного значения заинтересованы как теоретические, так и отраслевые правовые науки. Прежде всего методология истории понятий интересна для истории политических и правовых учений, поскольку задачей историка права, как считал B.C. Нерсесянц, является интерпретация прошлых политико-правовых доктрин [5, с. 11]. Именно их содержание, согласно О.Э. Лейсту, составляет понятийно-категориальный аппарат, отражающий различные понятия политической и правовой действительности [6]. Например, советская конституционная доктрина 1918 г. выражается в таких понятиях, как «социализм», «советы», «диктатура пролетариата», «советская федерация». Благодаря им раскрываются вопросы происхождения советского государства, его административно-территориального устройства, о целях и задачах конституционного строительства, методах решения политических вопросов, принципах социалистической правовой системы. Далее в статье методологические положения немецкой истории понятий будут обосновываться примерами из истории советского государства и права.

Целью статьи является адаптация инструментария немецкой истории понятий к юриспруденции, в которой понятия всегда были непосредственно связаны с толкованием юридических текстов. Тема толкования является широко разработанной в науке, начиная с дореволюционных юристов и правоведов советского периода вплоть до ученых-юристов наших дней. Под толкованием С.А. Степанов понимал «вне зависимости от побудительных оснований или комплекса факторов (экономических, политических, социологических, организационных и др.), от субъекта правотворческой инициативы, от уровня юридической силы предполагаемого правового акта... интерпретацию сложившихся, складывающихся в формальный и определенный юридический образ (модель) или предполагаемых (побуждаемых к возникновению) отношений, желательного или нежелательного правотворцу поведения субъектов» [12, с. 24]. Таким образом, толкование представляет собою процесс интерпретации определенной мыслительной модели или общественных отношений, независящий от социального контекста, самого субъекта права и места правового акта в иерархии. Позиция С.А. Степанова очень близка К. Скиннеру, который считал, что социальный контекст не влияет на содержание политико-правовых текстов, в то время как 
автор произведения подвержен влиянию других текстов похожей тематики (интертекстуальное взаимодействие) [10].

Задача любой интерпретации, по словам Д.И. Луковской, состоит в выявлении смысла текста, отражающего политические и правовые проблемы современников, в котором материализуются понятия, идеи и концепции. Однако тексты закона и политико-правового учения будут отличаться между собой по свойствам, ибо для полной интерпретации текста учения может анализироваться целое научное направление. Нормы права, как писал С.С. Алексеев, находят свое выражение через юридический язык и документы [9, c. 121-123]. Что касается политико-правовых учений, то они выражаются в том числе посредством политического языка и принимают форму политических программ, трактатов. Получается, что изучение понятий возможно только посредством интерпретации их использования в конкретных политических и правовых текстах.

Традицию изучения юридических понятий в русле историко-понятийного подхода заложил В.С. Нерсесянц. Он писал, что «история политико-правовой мысли - это история новых понятий права и государства и формирующихся на их основе новых политикоправовых теорий» [5, с. 10]. С точки зрения B.M. Сырых, понятия выполняют две функции: теоретическую, когда используются для анализа политико-правовых явлений, и методологическую, если они являются основой методологических правил [13, с. 95]. Н.М. Золотухина как историк права считает, что нужно разграничивать историческое и современное содержание основных юридических понятий [4, с. 227]. В этом смысле она воспроизводит позицию медиевиста А.Я. Гуревича относительно того, что «понятия, которыми неизбежно пользуются гуманитарные науки, сложились в Новое время, и применение этих понятий к обществам далекого прошлого чревато опасностью приписать им такие отношения, которых тогда не существовало...» [2, с. 7-8]. В связи с этим нужно обратить особое внимание при изучении истории политических и правовых учений на то, чтобы использовать понятия «государство» и «право» только в их историческом значении.

\section{Немецкая история понятий как методологический подход \\ В истории политических и правовых учений}

Развитие истории понятий как направления было связано с переосмыслением анализа идей: переход от канонического прочтения классических текстов к их контекстуализации. Эта эволюция, как метко подметил К. Гирц, была связана с тем, что предопределена общественными отношениями не сущность идей, а способы их выражения [1]. История понятий является крупным научным направлением в исследовании интеллектуальной истории. Именно оно дает правоведам инструментарий для анализа политической и правовой действительности. Социально-политические понятия составляют «ткань» любой политикоправовой доктрины. Как пишет А.Ф. Черданцев, «с точки зрения логики, семантики понятия в сфере права ничем не отличаются от любых других понятий» [16]. Справедливо говорил М.А. Исаев, что «знание старой юридической терминологии, несравнимой по богатству выражаемых оттенков с современной, окажет плодотворное влияние на профессиональное мышление нового поколения правоведов» [7, с. 110]. Таким образом, исторические понятия, используемые в юридической науке, могут объясняться при помощи современного категориального аппарата теории государства и права ради их лучшего уяснения, но только в объяснительных целях.

Немецкая история понятий стала популярна в российской науке благодаря переводу в 2014 г. некоторых статей из восьмитомного справочника «Основополагающие понятия, понимаемые исторически. Исторический словарь общественно-политического языка в Германии» ${ }^{2}$, вышедших в издании «Словарь основных исторических понятий» благодаря усилиям Германского исторического института в Москве [11]. Там раскрывается и анализируется историческая семантика, относящаяся к эволюции общественных институтов и экономики. Под «основными историческими понятиями» создатели словаря понимали не термины, используемые в научной литературе, а понятия, которые имели значение в ходе исторического процесса. Поэтому исследова- 
тельской задачей было изучить процесс исчезновения старого мира и создание современного [8, с. 23-24]. На основе анализа основных методологических положений немецкой истории понятий в статье показывается ее взаимодействие с историей политических и правовых учений.

Целью немецкого словаря являлась идентификация типов политических и социальных понятий, каждое из которых определяется в значении, используемом в современном немецком языке. Ключевая гипотеза словаря была в детальном анализе политических и социальных понятий, возникших в Европе нового времени. В ходе написания этого научного труда Р. Козеллек делал акцент на таких важных понятиях, которые «способствуют осмыслению структур» [8, с. 24]. Типы понятий будут проиллюстрированы примерами из истории Советского государства: «основные понятия, относящиеся к государственному строю» - советы, советская федерация, административно-территориальное устройство; «ключевые слова, относящиеся к политическому, экономическому и общественному устройству», - социализм, коммуна; «центральные понятия политических движений и их лозунги» - диктатура пролетариата, право наций на самоопределение. В истории политических и правовых учений основными темами, которые обсуждаются в политико-правовых доктринах, являются государственный строй, экономическое, социальное устройство и политические движения.

Лейтмотив словаря: «Описание современного мира посредством языка, его концептуализация и осознание с помощью тех понятий, которые являются не только понятиями прошлого, но также и нашими» $[8$, с. 25]. Основной эвристической презумпцией немецкой истории понятий было то, что старые понятия стали приобретать новое значение. Этот процесс может быть описан при помощи нескольких критериев [8, с. 27-32]:

1. Произошло расширение поля для применения понятий - это так называемая «демократизация» политического языка. Особенно ярко она видна перед Февральской революцией, когда был расцвет политической мысли разных направлений. Широта публичной сферы сохранялась до того момента, пока левые эсеры не были изгнаны из Советского правительства.

2. «Темпорализация» смысловых значений понятий означала процесс, когда понятия с течением времени стали приобретать новое понимание и заменяться аналогичными понятиями. В том числе сюда можно отнести возникновение из предшествующих понятий «измов»: коммуна - коммунизм, социум - социализм, конституция - конституционализм.

3. «Политизация» вокабуляра проявилась в том, что, во-первых, в политическом языке появились парные слова - диктатура / демократия, социализм / либерализм - и новые метафоры на их основе, во-вторых, политические лидеры стали инструментами мобилизации политических понятий.

В рамках как учебного курса, так и в исследовательских практиках науки истории политических и правовых учений описываемые в словаре явления «демократизации», «темпорализации» и «политизации» представлены в форме метанарратива, согласно Х. Уайту [15]. Хотя эти процессы не акцентированы в научных юридических работах, они, безусловно, прослеживаются при внимательном прочтении текстов. В связи с этим историко-понятийный методологический подход позволяет концептуализировать происходившие в российской истории процессы и увидеть изменения, которые отразились в юридических понятиях в ту или иную эпоху.

В российской юриспруденции процесс возникновения юридических понятий детально описал Н.Н. Тарасов, который выделил два способа их генезиса - историческая реконструкция и теоретическое конструирование. Для историков права, безусловно, приемлем только первый способ, поскольку второй не согласуется с принципом историзма, но, несомненно, удобен для теоретиков права. «Самым распространенным способом возникновения юридических понятий можно считать прохождение в профессиональной рефлексии юридического явления от простого знакового замещения до собственно понятия как знаниевой конструкции». Данный процесс первоначально не разделен с юридической деятельностью, в которой правовым явлениям просто присваивается определенное имя. Номинация еще далека от понятий как «знаниевых единиц». 
Только вследствие профессиональной рефлексии создаются юридические понятия «в форме помысленного, представленного в профессиональном юридическом мышлении явления». Описанный процесс можно проследить в ходе дискуссий при разработке и принятии Конституции РСФСР 1918 г., когда происходило содержательное формирование тех или иных конституционных понятий [14, с. 10-11].

\section{Ключевые положения немецкой истории понятий для истории политических и правовых учений}

В истории политических и правовых учений метод немецкой истории понятий следует описывать в инструментальном аспекте. Его можно охарактеризовать, если исходить из посылок, которые Р. Козеллек изложил во введении к словарю $[8$, с. 33-36]:

1. Акцент делается на историческом исследовании употребления слов в своей эпохе в различных социально-политических контекстах. Прежде всего изучается область применения слова, кому адресовано это понятие, для каких целей использовалось. Слова изучаются в их социальном и политическом контекстах, соотносятся с фактами действительности, и на этом основании делается «историко-критический» вывод. Например, понятие «диктатура пролетариата» применялось как в области политики (партийные собрания и митинги), так и в юридической сфере (использовалось в Конституции РСФСР 1918 г.). Это понятие было нацелено на классы пролетариата и беднейшего крестьянства и стало выгодным в том смысле, что позволяло легитимировать террор и иные явления революционной эпохи.

2. Диахронный принцип позволяет вытащить понятие из его исторического контекста, проследить его эволюцию во времени и дать соответствующий термин в современном языке для описания сути явления. Это «перевод существовавшего в прошлом смыслового содержания слов на язык, доступный нашему сегодняшнему пониманию». Также этот принцип позволяет увидеть значения слов, которые уже не соответствуют действительности. Например, «демократия» исконно была оппозицией диктатуре, а в понимании В.И. Ленина именно выражением самой настоящей демократии является диктатура пролетариата. В Coветском государстве классическое представление о демократии уже не будет соответствовать историческим условиям.

Контекстуальный анализ идей применялся в советской историко-правовой науке с 1960-х годов. Это было связано как с влиянием исторической науки на юриспруденцию, так и с серьезными теоретическими разработками в области истории политических и правовых учений в Институте государства и права. Тем не менее немецкая история понятий привносит новое для юриспруденции измерение - диахронный анализ понятий, который позволяет использовать термины современной теории государства и права для обозначения исторических понятий. Например, термином «государство» обозначается понятие «диктатура пролетариата», которое и составляет сущность Советского государства в 1917-1918 годах.

Лингвистический базис словаря является важным, поскольку использование только исторических методов не позволит вникнуть во всю глубину понятия и познать его с разных сторон. Также это еще связано с тем, что право является лингвистическим феноменом, по словам правоведа А.Б. Дидикина, к которому применимы лингвистические методы и грамматические конструкции [3, с. 77-78]. Методологические посылки Р. Козеллека в области лингвистики плодотворны для использования их в исследованиях по истории политических и правовых учений $[8$, с. 36-38]:

1. Лингвистический подход используется инструментально, чтобы понять историческую глубину понятия. "Семасиологический аспект» нацелен на выявление всех значений термина (слова). Например, понятие «диктатура пролетариата» будет рассмотрено в немецком понимании Ф. Энгельса и К. Маркса в XIX в. и в российском осмыслении В.И. Лениным в XX веке. Это будут очень сильно отличающиеся друг от друга представления о данном феномене. «Ономасиологический аспект», то есть аккумулирование всех наименований для вещи, будет плодотворен для правового исследования, поскольку множество идеологических терминов, обозначающих одно и то же понятие, использовалось члена- 
ми конституционной комиссии при разработке Конституции РСФСР 1918 года.

2. Различие между словом и понятием позволяет рассматривать последнее как «концентрат множества смысловых наполнений». «Все разнообразные реалии с их собственной терминологией схватываются словом... и приводятся к одному понятию». Слово - это лингвистический инструмент обозначения понятия, в то время как понятие является хранилищем смыслов разных исторических эпох. Важно подметить, что «значения слова могут точно определяться дефинициями, а понятия могут только интерпретироваться». Слово «советский конституционализм» как сочетание прилагательного «советский» и существительного «конституционализм» становится понятием, характеризующим советскую политико-правовую доктрину, только благодаря таким другим понятиям, его раскрывающим, как «социализм», «советы», «диктатура пролетариата» и т. д.

\section{Выводы}

Итак, взаимодействие немецкой истории понятий и истории политических и правовых учений происходит в нескольких основных аспектах.

Во-первых, типы понятий, представленные в немецком словаре, соответствуют тем категориям, которые анализируются в рамках истории политических и правовых учений. Получается, что расхождений между этими двумя науками в классификации понятий нет, а существуют лишь содержательные отличия в рассматриваемых понятиях.

Во-вторых, процессы «демократизации», «темпорализации» и «политизации» политического и юридического языка так или иначе исследовались в истории политических и правовых учений. Немецкая история понятий, лишь акцентируя внимание на данных явлениях, обозначает их как значимые категории исторического анализа.

B-третьих, принципы контекстуального и диахронного анализа понятий в своей совокупности представляют строго научный метод, позволяющий поместить юридическое понятие в социальный, политический, культурный и экономический контексты, а затем адаптировать при помощи использования современ- ного юридического языка это понятие для конкретных исследовательских задач.

B-четвертых, лингвистические принципы, используемые в немецкой истории понятий, делают возможным восполнить пробел, существующий в истории политических и правовых учений. Связан он прежде всего с тем, что термин и понятие принципиально правоведами не различаются в нарративных исторических исследованиях. Использование данных наработок для анализа юридического языка позволит не только найти похожие слова, но и систематизировать правовой вокабуляр для дальнейшего его обобщения и изучения.

\section{ПРИМЕЧАНИЯ}

${ }^{1}$ Статья подготовлена при поддержке гранта РФФИ № 20-011-00779 «Историография, источниковедение и методология истории политических и правовых учений: теоретические и прикладные проблемы исследовательских практик».

The article was funded by RFBR, grant no. 20011-00779 "Historiography, Source Studies and Methodology of the history of political and legal doctrines: theoretical and applied problems of research practices".

${ }^{2}$ Название словаря по-немецки: «Geschichtliche Grundbegriffe. Historisches Lexikonzurpolitischsozialen Sprache in Deutschland».

\section{СПИСОК ЛИТЕРАТУРЫ}

1. Гирц, К. Интерпретация культур / К. Гирц. - М., 2004. - 557 c.

2. Гуревич, А. Я. Категории средневековой культуры / А. Я. Гуревич. - М., 1984. - 350 с.

3. Дидикин, А. Б. Право как лингвистический феномен: к постановке проблемы / А. Б. Дидикин // Проблемы методологии и философии права : сб. ст. участников III Междунар. круглого стола (г. Самара, 26-27 февр. 2016 г.). - Самара : Изд-во Самар. гуманит. акад., 2016. - С. 76-86.

4. Золотухина, Н. М. Историческое и современное значение политико-юридической терминологии / Н. М. Золотухина // Lex Russica (Русский закон). - 2016. - № 10. - С. 202-230.

5. История политических и правовых учений : учеб. для вузов / под общ. ред. В. С. Нерсесянца. 4-е изд. - М., 2004. - 944 с.

6. История политических и правовых учений : учеб. для вузов / под ред. О. Э. Лейста и В. А. Томсинова. - 3-е изд., доп. - М., 2009. - 576 с. 
7. Кодан, С. В. Формирование и становление понятийно-исторического подхода в европейской и отечественной социально-гуманитарной науке / С. В. Кодан // Историко-правовые проблемы: новый ракурс. - 2019. - № 4. - С. 95-112.

8. Козеллек, Р. Введение (Einleitung) / Р. Козеллек // Словарь основных исторических понятий : избранные статьи в 2 т. Т. 1 / сост. Ю. Зарецкий, К. Левинсон, И. Ширле. - М., 2014. - С. 23-44.

9. Луковская, Д. И. Политические и правовые учения: историко-теоретический аспект / Д. И. Луковская. - Л., 1985. - 161 с.

10. Скиннер, К. Значение и понимание в истории идей / К. Скиннер // Кэмбриджская школа: теория и практика интеллектуальной истории / сост. Т. Атнашев, М. Велижев. - М., 2018. - С. 53-122.

11. Словарь основных исторических понятий : избранные статьи в 2 т. Т. 1 / сост. Ю. Зарецкий, К. Левинсон, И. Ширле. - М., 2014. - 736 с.

12. Степанов, С. А. Интерпретация интерпретации / С. А. Степанов // Российский юридический журнал. - 2017. - № 6 (117). - С. 23-33.

13. Сырых В. М. История и методология юридической науки : учебник / В. М. Сырых. - М., 2012. $464 \mathrm{c}$.

14. Тарасов, Н. Н. К вопросу о предмете общей теории права и теоретических понятиях / Н. Н. Тарасов // Российский юридический журнал. - 2015. № 6(105). - С. 9-21.

15. Уайт, Х. Метаистория: Историческое воображение в Европе XIX в. / Х. Уайт. - Екатеринбург, 2002. $-528 \mathrm{c}$.

16. Черданцев, А. Ф. Логико-языковые феномены в юриспруденции: монография / А. Ф. Черданцев. - М., 2012. - 320 с.

\section{REFERENCES}

1. Girc K. Interpretatsiya kultur [Interpretation of Cultures]. Moscow, 2004. 557 p.

2. Gurevich A.Ya. Kategorii srednevekovoy kultury [Categories of Medieval Culture]. Moscow, 1984.350p.

3. Didikin A.B. Pravo kak lingvisticheskiy fenomen: k postanovke problemy [Law as a Linguistic Phenomenon: Towards Problem Statement]. Problemy metodologii i filosofii prava: sb. st. uchastnikov III Mezhdunar. kruglogo stola. 26-27 fevr. $2016 \mathrm{~g}$. [Problems of Methodology and Philosophy of Law]. Samara, Izd-vo Samar. gumanit. akad., 2016, pp. 76-86.

4. Zolotuhina N.M. Istoricheskoye i sovremennoye znacheniye politiko-yuridicheskoy terminologii [Historical and Modern Meaning of Political and Legal Terminology]. Lex Russica (Russkiy zakon), 2016, no. 10, pp. 202-230.
5. Nersesyants V.S., ed. Istoriya politicheskikh i pravovykh ucheniy: ucheb. dlya vuzov [History of Political and Legal Doctrines. Textbook for Universities]. Moscow, 2004. 944 p.

6. Leyst O.E., Tomsinov V.A., eds. Istoriya politicheskikh i pravovykh ucheniy: ucheb. dlya vuzov [History of Political and Legal Doctrines. Textbook for Universities]. Moscow, 2009. 576 p.

7. Kodan S.V. Formirovaniye i stanovleniye ponyatiyno-istoricheskogo podkhoda $\mathrm{v}$ evropeyskoy i otechestvennoy sotsialno-gumanitarnoy nauke [Formation and Development of a ConceptualHistorical Approach in European and Domestic Social and Humanitarian Science]. Istoriko-pravovyye problemy: novyy rakurs [Historical and Legal Problems: ANew Perspective], 2019, no. 4, pp. 95-112.

8. Kozellek R. Vvedeniye (Einleitung) [Introduction (Einlitung)]. Zaretskiy Yu., Levinson K., Shirle I., eds. Slovar osnovnykh istoricheskikh ponyatiy: izbrannyye stati $v 2 t$. T. 1 [Dictionary of Basic Historical Concepts: Selected Articles in 2 volumes. Vol. 1]. Moscow, 2014, pp. 23-44.

9. Lukovskaya D.I. Politicheskiye i pravovyye ucheniya: istoriko-teoreticheskiy aspekt [Political and Legal Doctrines: Historical and Theoretical Aspect]. Leningrad, 1985. $161 \mathrm{p}$.

10. Skinner K. Znacheniye i ponimaniye $\mathrm{v}$ istorii idey [Meaning and Understanding in the History of Ideas]. Atnashev T., Velizhev M., eds. Kembridzhskaya shkola: teoriya i praktika intellektualnoy istorii [The Cambridge School: Theory and Practice of Intellectual History]. Moscow, 2018, pp. 53-122.

11. Zaretskiy Yu., Levinson K., Shirle I. Slovar osnovnykh istoricheskikh ponyatiy: izbrannyye stati $v$ 2t. T. 1 [Dictionary of Basic Historical Concepts: Selected Articles in 2 volumes. Vol. 1]. Moscow, 2014. 736 p.

12. Stepanov S.A. Interpretatsiya interpretatsii [Interpretation of Interpretation]. Rossiyskiy yuridicheskiy zhurnal, 2017, no. 6 (117), pp. 23-33.

13. Syrykh V.M. Istoriya i metodologiya yuridicheskoy nauki: uchebnik [History and Methodology of Legal Science: Textbook]. Moscow, 2012. 464 p.

14. Tarasov N.N. K voprosu o predmete obshchey teorii prava i teoreticheskikh ponyatiyakh [On the Subject of the General Theory of Law and Theoretical Concepts]. Rossiyskiy yuridicheskiy zhurnal, 2015, no. 6(105), pp. 9-21.

15. Uayt Kh. Metaistoriya: Istoricheskoye voobrazheniye $v$ Evrope XIX v. [Metahistory: Historical Imagination in $20^{\text {th }}$ Century Europe]. Ekaterinburg, 2002. 528 p.

16. Cherdantsev A.F. Logiko-yazykovyye fenomeny $v$ yurisprudentsii: monografiya [LogicLinguistic Phenomena in Jurisprudence: Monograph]. Moscow, 2012. 320 p. 


\section{Information About the Author}

Kirill S. Korovin, Postgraduate Student, Department of Theory of State and Law, Ural State Law University, Komsomolskaya St, 21, 620137 Yekaterinburg, Russian Federation, korovinscience@yandex.ru, https://orcid.org/0000-0003-1746-2458

\section{Информация об авторе}

Кирилл Сергеевич Коровин, аспирант кафедры теории государства и права, Уральский государственный юридический университет, ул. Комсомольская, 21, 620137 г. Екатеринбург, Российская Федерация, korovinscience@yandex.ru, https://orcid.org/0000-0003-1746-2458 